\title{
Research on the network sports news entertainment based on the multi- data analysis
}

\author{
Yang Yang ${ }^{1, a}$, Zhaozhong Jin ${ }^{2, b}$, Dong Chen ${ }^{3, c}$ \\ 1,3 Hebei Chemical\&Pharmaceutical College, China \\ ${ }^{2}$ Hebei College of Industry and Technology, China \\ a35949162@qq.com, b50954099@qq.com, c419876845@qq.com
}

Keywords: Sports Network news; entertainment; multi-data analysis

\begin{abstract}
With the rapid development of economy, rapid integration of science and technology network, mass sports structure has become into a rapid differentiation and re-integration phase. Network sports entertainment is currently one of the important characteristics of sports journalism. Sports entertainment on the Internet is currently one of the most important characteristics of sports journalism. This paper mainly analyzes the current situation, problems and causes of network sports entertainment, and then put forward some problems that should be avoided.
\end{abstract}

\section{Introduction}

Sports news reports is the key point that the network media pays attention to. Our major web has set up sports news channel in order to attract hit and viewing rate. The spread of Internet sports news has broken the traditional media monopoly status on sports news, network media, television and newspapers which has formed vertical pattern. Consequently, network sports entertainment becomes one of the main characteristics of sports news.This paper mainly focuses on the current situation, problems and causes of the more and more serious phenomenon of network sports news entertainment, and also discusses the problems that should be avoided.

\section{What is network sports entertainment?}

What is network sports entertainment? This article summarizes it as follows: in the mode of narrative, using "gossip" , mainly full of man-made "entertainment" element; in the contents of the report, outstanding the "entertainment" element in sports activities; in the news effect, emphasize the interest and attraction. After random search for the article title of 2011 China football super league in show sports project, found that "entertainment" elements meet the eye everywhere: such as "Shenhua hope home court ended nine rounds Su Jin zoric scored on old friends Hengda training team hard Ka Kong singing to the sky", which can be seen in tab1.

While some excessive entertainment news, such as "Beauty torn clothes to help the country foot" crossed the moral bottom line, causing some negative problems:

First of all, the excessive entertainment sports news network will lead to news report deviates from the basic requirement of news authenticity. In the pursuit of entertainment, reporters unexpectedly use his imagination to fiction sports news content; as a result, false news flood situation is very severe in the network sports news.

Secondly, excessive entertainment in the Internet sports news leads to news smell of a single value. No diversity do not undertake the responsibility of comprehensive coverage of sports information, disseminating of sports culture and heritage sports civilization

Thirdly, excessive entertainment in network sports news lead to lacking of humanistic care. insulting, vulgar, serious violations of others privacy and even personality reports are full with the Internet sports news, that is a serious departure from the sports humanistic spirit and the concept of the people-oriented news. 
Tab1. The network sports channel and site name

\begin{tabular}{|c|c|c|c|c|c|}
\hline Site name & Channel & $\begin{array}{c}\text { Top } \\
\text { news }\end{array}$ & Blog & Forum & Lace \\
\hline Sina sports & $\begin{array}{l}\text { The Olympic Games, football, China } \\
\text { International Football, basketball, NBA, } \\
\text { synthesis All sports }\end{array}$ & $\sqrt{ }$ & $\sqrt{ }$ & & $\sqrt{ }$ \\
\hline $\begin{array}{l}\text { NetEase } \\
\text { Sports }\end{array}$ & $\begin{array}{c}\text { Fantasy football, European football live, Lining } \\
\text { community, CBA's official website, in Asian } \\
\text { Games }\end{array}$ & $\sqrt{ }$ & & $\sqrt{ }$ & \\
\hline Sohu & Football, basketball (NBA) synthesis, & & $\sqrt{ }$ & & $\sqrt{ }$ \\
\hline $\begin{array}{l}\text { China } \\
\text { Sports } \\
\text { Online }\end{array}$ & $\begin{array}{l}\text { The reading room, cangjing Ge, the picture in } \\
\text { the center, sports and I know }\end{array}$ & & $\sqrt{ }$ & $\sqrt{ }$ & \\
\hline China.com & $\begin{array}{c}\text { Comprehensive sports, basketball, CBA; } \\
\text { Domestic and international football, UEFA } \\
\text { Champions League }\end{array}$ & $\sqrt{ }$ & $\sqrt{ }$ & & $\sqrt{ }$ \\
\hline
\end{tabular}

\section{The research of current situation of network sports news entertainmentization based on multi-data analysis}

Network sports and entertainment group is a network-based communications media, through the same sports hobbies, network sports groups spontaneously form with purpose of sports and entertainment events, sports friends, reducing psychological pressure, exchanging experiences about sports. In the process, it results in emerging sport groups-groups of sports entertainment network. To this network society research on sports groups, we are still in the blank stage. So we need further research on the status of development of network sports and entertainment groups, management, social effects and responses, etc., in order to continuously improve their developments, thus promoting continuous progress of China's sports undertakings.

Table1 show that making new friends in the crowd to participate in sports and entertainment network, playing sports together and experiences communication to join the network is the main reason for sports entertainment group. It reflects the desire of our people currently on emotional communication. Network sports and entertainment group is the exchange of experience, to improve the technical level of disposable leisure time, to make friends with the same interests about the ball, health and entertainment purposes, becoming a relatively loose network of sports groups. there is no deny that online sports have many significant roles in many aspects, such as promoting health, promote economic growth, and fostering a good caber environment and remove network diseases.

Table2.the purpose on participation in sports and entertainment network groups

\begin{tabular}{|c|c|}
\hline Purpose & Proportion \\
\hline Making new friends & $29 \%$ \\
\hline experiences communication & $22 \%$ \\
\hline Facilitating communication & $13 \%$ \\
\hline Playing sports together & $31 \%$ \\
\hline Some organized competitions & $4 \%$ \\
\hline
\end{tabular}

Since the 1990s, entertainment has become an important tendency of global media. According to an investigation of the national association of journalists, media reports are mainly composed of hard news in the $90 \mathrm{~s}$ and in the late 90s the ratio of hard news to entertainment news has reached 25\%:40\%. According to relevant Investigations, in sports news network domain, the ratio of hard news to entertainment news has reached 20\%:61\%, it can be seen that by extensively using of entertainment news style, making network sports news entertainment reach an unprecedented level. 


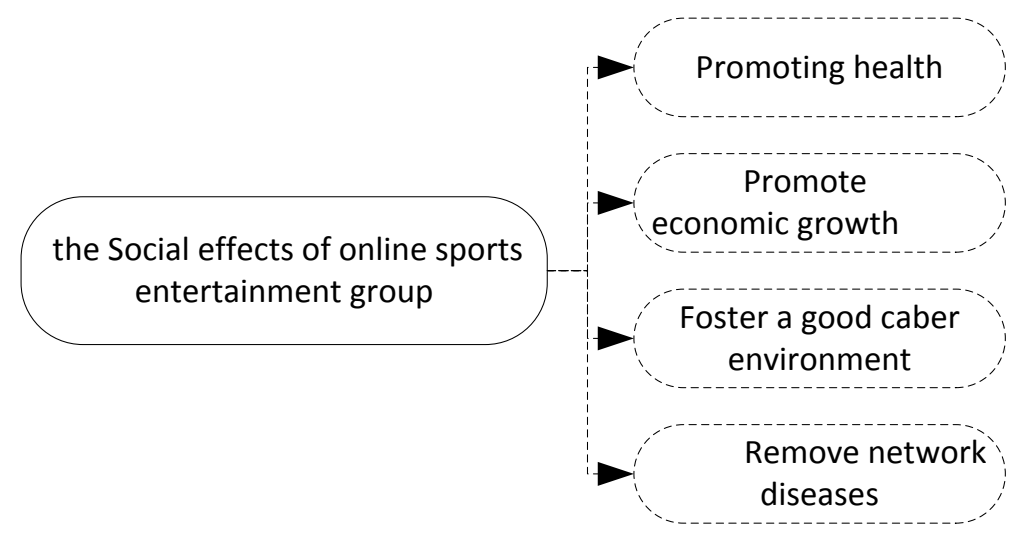

Fig1. The social effects of online sports entertainment

\section{The causes of the current network sports news entertainmentization based on multi-data analysis}

From the perspective of social causes, network sports news entertainment meets the audience's psychological needs. In the network world, people try to find some entertain elements, releasing or escaping from temporary stress. So the news full of entertainment has become one of thither choices, and enlarging the news entertainment and interest also become an important feature of the Internet sports news.

From the perspective of market, network sports news entertainment is the result of market competition. To meet the needs of the audience, improve the website traffic; launch some gossip news and lace news to attract eye attention.

From the media employees' psychological point of view, sports network news entertainment has something to do with its younger staff and their value concept. Currently the staff engaged in network sports news are all youth almost ,they smell of avant-garde fashion, and often one-sided pursuit of interesting, readable, entertaining, and ignores the authenticity and objectivity such important news value concept, these are all easy to cause the overgrowth of the network news entertainment.

From the perspective of intercultural communication, entertainment orientation of news can be traced back to the western yellow journalism at the end of the nineteenth century. In the late 90's, Simpson murder trial, the death of Princess Diana and Clinton president scandal, become the three landmark events in the news entertainment. The influence of Western media entertainmentization trend is one of the important causes of China's Internet sports news entertainmentization.

\section{The countermeasures to the Internet sports news entertainment based on multi-data analysis}

Firstly, to improve network sports news journalists' sense of responsibility and aesthetic taste. Online sports news workers should have the correct concept of news value and good professional ethics. Facing a tidal wave of network sports entertainment, they should strictly discipline themselves ,to be objective and fair, in the report of sports news, should use reasonable way of entertainment, remain the moral bottom line, only in this way, can effectively prevent the negative effect of network sports news entertainment

Secondly, network sports news entertainment should stick to their basic principle. News and information must be true; this is the most basic principle. Sports not only have the function of entertainment by watching sports, we can also see athletes' tenacious spirit, team spirit and patriotic spirit. Therefore, network sports news entertainment should not blindly pursue negative reports, should show more active in sports news. In this way can online sports news entertainment orbit in healthy track, producing good communication effect? 


\section{Conclusion}

Network sports entertainment is currently one of the important characteristics of sports journalism. Sports entertainment on the Internet is currently one of the important characteristics of sports journalism. If accurately use entertainment means to meet the various needs of the audience, the road of network sports news entertainment will be wider. However, audience's demand is diverse, if the sports news put much emphasis on entertainment but ignores the social news authenticity and other functions, failing to meet the demand of the audience and suffering failure eventually. the network sports news worker's responsibility should attach much importance.

\section{References}

[1] Li Liangrong: Localization and entertainment —— Two big trends of America news media [J], China's electronic and Internet press, 2003 (6).

[2] Zheng Gencheng: Ethical reflection of media entertainment [J], the division of Hunan Normal Van University journal of social science, 2006 (3).

[3] Luo Xiao: Analysis on the theoretical interpretation and case study of Chinese current sports news entertainment [J], 2005 (6).

[4] Wang Kaizhen.Social Transformation and the Chinese Urban Community Sports Development [J]. Chinese academic literature online publishing pool, 2004. 